\title{
The Compensatory Role of the Frontal Cortex in Mild Cognitive Impairment: Identifying the Target for Neuromodulation
}

\author{
Olga R. Dobrushina*, Zukhra Sh. Gadzhieva, Sofya N. Morozova, Elena I. Kremneva, Marina \\ V. Krotenkova, and Larisa A. Dobrynina
}

Research Center of Neurology, Moscow, Russia

\begin{tabular}{|c|c|}
\hline Abs & ract \\
\hline $\begin{array}{l}\text { Introduction: Development of individualized neuromod } \\
\text { a feasible practical goal. Preliminary research explorin } \\
\text { neuroimaging is necessary. Methods: Twenty-one olde } \\
\mathrm{MCI} \text {, underwent functional MRI while performing two } \\
\text { counting. A functional activation and connectivity analys } \\
\text { covariate. This variable represented the difference be } \\
\text { Rating Inventory of Executive Function (BRIEF) and the } \\
\text { Assessment (MoCA) Scale, an ability to compensate for } \\
\text { activation of areas within the frontoparietal control netwo } \\
\text { the pre-SMA, the lateral premotor cortex, and the cereb } \\
\text { pre-SMA was observed during the tasks. The BRIEF-I } \\
\text { dorsolateral prefrontal cortex (LDLPFC) and, second, w } \\
\text { task. Conclusion: The developed neuroimaging techni } \\
\text { within the LDLPFC in patients with MCI. }\end{array}$ & $\begin{array}{l}\text { ulation techniques for mild cognitive impairment (MCI) is } \\
\text { the brain-level compensatory reserves on the base of } \\
\text { r adults, representing a continuum from healthy norm to } \\
\text { executive tasks-a modified Stroop task and selective } \\
\text { is were conducted with the inclusion of a BRIEF-MoCA } \\
\text { tween the real-life performance measured by Behavior } \\
\text { level of cognitive deficit measured by Montreal Cognitive } \\
\text { impairment. Results: Both tasks were associated with } \\
\text { rk, along with the supplementary motor area (SMA) and } \\
\text { ellum. A widespread increase in the connectivity of the } \\
\text { MoCA value correlated, first, with connectivity of the left } \\
\text { ith enrollment of the occipital cortex during the counting } \\
\text { que allows identification of the functionally salient target }\end{array}$ \\
\hline Keywords: mild cognitive impairment; executive functio & רs; fMRI; functional connectivity \\
\hline $\begin{array}{l}\text { Citation: Dobrushina, O. R., Gadzhieva, Z. Sh., Morozova, S. N., } \\
\text { compensatory role of the frontal cortex in mild cognitive impairment: Id } \\
\text { http://dx.doi.org/10.15540/nr.6.1.3 }\end{array}$ & $\begin{array}{l}\text { Kremneva, E. I., Krotenkova, M. V., \& Dobrynina, L. A. (2019). The } \\
\text { entifying the target for neuromodulation. NeuroRegulation, 6(1), 3-14. }\end{array}$ \\
\hline $\begin{array}{l}\text { *Address correspondence to: Olga R. Dobrushina, PhD, Research } \\
\text { Fellow, Third Neurological Department, Research Center of } \\
\text { Neurology, } 125367 \text { Volokolamskoe shosse, 80, Moscow, Russia. } \\
\text { Email: dobrushina@mipz.ru }\end{array}$ & $\begin{array}{l}\text { Edited by: } \\
\text { Rex L. Cannon, PhD, Knoxville Neurofeedback Group, Knoxville, } \\
\text { Tennessee, USA }\end{array}$ \\
\hline $\begin{array}{l}\text { Copyright: (C 2019. Dobrushina et al. This is an Open Access article } \\
\text { distributed under the terms of the Creative Commons Attribution } \\
\text { License (CC-BY). }\end{array}$ & $\begin{array}{l}\text { Reviewed by: } \\
\text { Rex L. Cannon, PhD, Knoxville Neurofeedback Group, Knoxville, } \\
\text { Tennessee, USA } \\
\text { Randall Lyle, PhD, Mount Mercy University, Cedar Rapids, lowa, } \\
\text { USA }\end{array}$ \\
\hline
\end{tabular}

\section{Introduction}

Neurocognitive disorders are a major burden of the aging population (Hugo \& Ganguli, 2014). While dementia is a frequent cause of death, even mild cognitive impairment $(\mathrm{MCl})$ is associated with increased mortality (Bae et al., 2018). The incidence of $\mathrm{MCl}$ is high: $6.7 \%$ for ages $60-64,8.4 \%$ for $65-69$, with a subsequent increase up to $25.2 \%$ for ages 80 84. Neurocognitive disorders dramatically affect quality of life (Hugo \& Ganguli, 2014), and a key contributor to maladaptation is executive dysfunction (Marshall et al., 2011).
Treatment options for $\mathrm{MCl}$ are limited. Cholinesterase inhibitors, commonly used to treat dementia, along with other drugs showed no benefit in $\mathrm{MCl}$ (Petersen et al., 2018). Thus, the development of nonpharmacological approaches for the improvement of cognitive functioning in $\mathrm{MCl}$ is feasible. The clinical application of neurophysiological research has resulted in an increased use of neuromodulation techniques, such as repetitive transcranial magnetic stimulation (rTMS) and transcranial direct current stimulation (tDCS). While there is currently insufficient evidence to 
evaluate the efficacy of these methods in $\mathrm{MCl}$, some trials show promising results (Drumond Marra et al., 2015).

In a study by Drumond Marra et al. (2015), 34 patients with $\mathrm{MCl}$ were randomized for 10 sessions of highfrequency rTMS over the left dorsolateral prefrontal cortex (LDLPFC) or sham TMS. The intervention resulted in enhanced everyday performance according to the Rivermead Behavioural Memory Test, with the effect lasting at least one month (Drumond Marra et al., 2015). According to another study, rTMS of the LDLPFC in $\mathrm{MCl}$ leads to compensatory recruitment of the frontoparietal control network (FPCN), which may explain its beneficial effects (Solé-Padullés et al., 2006). Artificial stimulation during neuromodulation has similarities with the natural functional adaptation of the brain observed in cognitive decline-increased recruitment of the cortex during challenging tasks, especially in the frontal areas (Clément, Gauthier, \& Belleville, 2013; Naumczyk et al., 2017). This mechanism is also in line with the gold standard of neuropsychological rehabilitation: since memory training is proven to be ineffective, promoting compensations that improve everyday life is the main aim of rehabilitation (Wilson, Gracey, Evans \& Bateman, 2009). At the same time, the importance of adjustment of the neuromodulation protocol on the base of neuroimaging is discussed, since $\mathrm{MCl}$ is a heterogenous phenomenon (Anderkova, Eliasova, Marecek, Janousova, \& Rektorova, 2015). Along with evaluation of the clinical efficacy of neuromodulation, it is important to continue improving these techniques.

In the current study, we evaluate the organization of executive functions in $\mathrm{MCl}$ in conjunction with everyday functioning. As an a priori hypothesis, we assume that the top-down regulatory influences of the frontal cortex during an artificial task reflect the same brain-level mechanisms that allow compensation for cognitive decline in real life. We aim to reveal these mechanisms using functional connectivity analysis. This study is forming a basis for the development of individualized neurostimulation approaches.

\section{Methods}

\section{Participants}

Participants were selected among older adults (45 years and older) who volunteered to participate in the project. First, a structured interview and a neurological examination were performed to exclude participants with neurological and psychiatric diseases other than $\mathrm{MCl}$. Second, a neuroimaging inclusion criterion was applied; that is, a structural brain MRI scan graded as 0 or 1 on the Fazekas scale (absent or minor white matter lesions; Fazekas, Chawluk, Alavi, Hurtig, \& Zimmerman, 1987). Any other brain damage, including any findings with a Fasekas rating of 2 or higher, served as an exclusion criterion, in order to avoid excessive heterogeneity of the sample. The study included 21 adults aged 4571 years (median 57; 1 st quartile 52; 3rd quartile $59.5)$, representing a continuum from healthy norm to $\mathrm{MCl}$. Subjects with lower cognitive levels did not enter the study, because of their failure to fit into the Fasekas 0-1 range. We did not aim to define a clear margin between normal aging and $\mathrm{MCl}$ within the scope of the study, as this is problematic in this borderline group.

All participants underwent a cognitive assessment, performed by the same trained examiner, that included the Montreal Cognitive Assessment Scale (MoCA; Nasreddine et al., 2005), the Frontal Assessment Battery (FAB; Dubois, Slachevsky, Litvan, \& Pillon, 2000), the Luria Memory Words Test (Luria, 1980), and the Trail Making Test (Delis, Kaplan, \& Kramer, 2001). Executive functioning in daily life was self-rated using the Behavior Rating Inventory of Executive Function (BRIEF; Gioia, Isquith, Guy, \& Kenworthy, 2000). To account for emotional factors, the Hospital Anxiety and Depression Scale (HADS) was also included into the assessment (Zigmond \& Snaith, 1983).

The protocol and informed consent form were approved by the Ethics Committee and the Institutional Review Board of the Research Center of Neurology, and all participants signed the informed consent form before entering the study.

fMRI acquisition and preprocessing. MRI was performed with a Siemens MAGNETOM Verio 3T scanner (Erlangen, Germany) located at the Research Center of Neurology. Functional images were acquired using $\mathrm{T} 2^{*}$-gradient echo imaging sequences (TR $3000 \mathrm{~ms}$, TE $30 \mathrm{~ms}$, FA 90, voxel size $3 \times 3 \times 3 \mathrm{~mm}^{3}$, FOV $192 \mathrm{~mm}$ ). Four extra functional volumes were acquired at the start of the session and discarded by the scanner software in order to prevent the usage of artifactual data obtained before the magnetic equilibrium is reached. A three-dimensional structural image consisted of a sagittal T1-weighted 3D-MPRAGE sequence (TR $1900 \mathrm{~ms}$, TE $2.5 \mathrm{~ms}$, FA 9 , voxel size $1 \times 1 \times 1 \mathrm{~mm}^{3}$, FOV $250 \mathrm{~mm}$ ).

All participants underwent two fMRI sessions with a block design with an interval of no less than 48 hours: 
a simplified version of a classical Stroop task (Stroop; Stroop, 1935) and an original selective counting paradigm developed at our center (Count). Each task consisted of four active and four rest blocks with a duration of $30 \mathrm{~s}$ (4 min total). During the Stroop session, the rest periods (fixation cross) alternated with a slideshow consisting of 20 stimuli ( $1.5 \mathrm{~s}$ each): a word indicating a color (red, blue, green, or yellow) was presented on the display, written in either congruent or conflicting font color. The participants were required to inwardly answer "yes" if the color of the word corresponded to the text. During the Count task, eyes-open rest periods alternated with the selective counting task: the participants were instructed to inwardly count up from one, omitting the numbers divisible by three (one, two, four, five, seven, etc.). Before both sessions, a 5- to 10-min training was performed outside the scanner. Such simplified variants of executive tasks specifically address the population of cognitively impaired patients and allow further transfer of the technology to patients with dementia.

Data were analyzed in MATLAB 2017b (http://www.mathworks.com), with the use of the statistical parametric mapping software SPM12 (http://www.fil.ion.ucl.ac.uk/spm) and CONN17f (http://www.nitrc.org/projects/conn). A standard preprocessing protocol was utilized and included motion correction, slice-timing correction, realignment, co-registration of functional and anatomical data, normalization into the Montreal Neurological Institute (MNI) stereotactic space, segmentation of the average structural image into tissue images (grey matter, white matter, and CSF volumes) and smoothing with an 8-mm Gaussian kernel. All coordinates are presented in MNI space $(x, y, z)$.

To evaluate block consistency, the raw activation data were extracted with the use of the MarsBaR toolbox (http://marsbar.sourceforge.net), and a comparison between blocks was performed with the SPSS v22 (http://www.ibm.com/products/spssstatistics) package using a general linear model.

The functional neuroimaging results were rendered and visualized with the use of the MRIcroGL program (http://www.cabiatl.com/mricrogl).

Functional activation and connectivity analysis. Statistical parametric maps for each participant were calculated using a general linear model. To compute group activation maps, a second-level analysis was performed using one-sample T-tests with $p<.001$ uncorrected at the voxel level.

The task-related functional connectivity analysis aimed to evaluate the regulatory influences of the areas within the frontal lobes during the executive tasks. On the basis of the activation analysis for both the Stroop and Count conditions, we identified the key areas within the frontal cortex, and the regions of interest (ROIs) for the connectivity analysis were constructed as spheres of $10-\mathrm{mm}$ radius around the centers of these clusters (see Results section, Table 2).

Based on the assumption that the task-based connectivity of the frontal areas might correlate with the ability to compensate for cognitive decline in real life, we included the second-level covariates BRIEF and BRIEF-MoCA into the analysis. To compute the BRIEF-MoCA value, we transformed absolute BRIEF and MoCA scores into scales from 0 to 10 (MoCA: 0 for the lower and 10 for the higher value in the sample, BRIEF: 0 for the higher and 10 for the lower value in the sample) and then calculated the difference between these ratings. A higher BRIEFMoCA value represents better executive functioning in everyday life, despite a cognitive deficit.

Denoising of the functional data included linear regression of the confounding effects of the white matter, CSF, correction for realignment and scrubbing, and the application of a band-pass filter of $0.008-0.09 \mathrm{~Hz}$. Functional connectivity evaluation was performed using Pearson's correlation analysis with a subsequent Fischer transformation during the first-level analysis. Multiple-comparison adjustments were implemented with a false discovery error rate (FDR) of $q<.05$ at the cluster-level, given a voxelwise statistical threshold of $p<.001$ uncorrected. A Bonferroni correction was applied for the number of ROls entered into the ROI-to-voxel connectivity analysis.

\section{Results}

Cognitive assessment data. The results of the cognitive assessment are summarized in Table 1. According to the MoCA scale (Nasreddine et al., 2005), the study sample included a continuum from healthy norm to $\mathrm{MCl}$, with a range of 25-30. The evaluation of executive functions with the $F A B$ revealed no significant impairment (score 17-18 of 18), while the results of the more sensitive TMT indicated some decline in performance. According to the BRIEF, the participants experienced variable 
difficulties with self-regulation in daily life. While these tests gave us only a general impression regarding the level of executive functioning, this battery, in combination with the neuroimaging procedure, was already very demanding for our sample of older adults.
HADS ratings indicated that the majority of the subjects did not have clinically significant anxiety or depression, and it is thus unlikely that emotional factors had any valuable influence on cognitive performance.

\section{Table 1}

The results of the cognitive assessment.

\begin{tabular}{|c|c|c|c|c|c|}
\hline & Median & Min & First Quartile & Third Quartile & Max \\
\hline $\begin{array}{l}\text { Montreal Cognitive Assessment } \\
\text { Scale (MoCA) }\end{array}$ & 28 & 25 & 25 & 29 & 30 \\
\hline $\begin{array}{l}\text { Frontal Assessment Battery } \\
\text { (FAB) }\end{array}$ & 18 & 17 & 17 & 18 & 18 \\
\hline $\begin{array}{l}\text { Behavior Rating Inventory of } \\
\text { Executive Function (BRIEF) }\end{array}$ & 123 & 88 & 107 & 139 & 156 \\
\hline $\begin{array}{l}\text { Luria Memory Words Test } \\
\text { (quantity of words memorized } \\
\text { after } 5 \text { trials, of 10) }\end{array}$ & 9 & 7 & 9 & 10 & 10 \\
\hline $\begin{array}{l}\text { Luria Memory Words Test } \\
\text { (quantity of words recalled after } \\
\text { 30-min interference, of } 10 \text { ) }\end{array}$ & 8 & 2 & 7 & 9 & 10 \\
\hline $\begin{array}{l}\text { Trail Making Test, part A } \\
\text { (time in seconds) }\end{array}$ & 34 & 21 & 28.5 & 42.5 & 65 \\
\hline $\begin{array}{l}\text { Trail Making Test, part A } \\
\text { (normalized percentile) }\end{array}$ & 30 & 10 & 10 & 60 & 80 \\
\hline $\begin{array}{l}\text { Trail Making Test, part B } \\
\text { (time in seconds) }\end{array}$ & 89 & 54 & 59.5 & 103.5 & 154 \\
\hline $\begin{array}{l}\text { Trail Making Test, part B } \\
\text { (normalized percentile) }\end{array}$ & 20 & 10 & 10 & 60 & 70 \\
\hline HADS Anxiety & 5 & 0 & 2 & 7.5 & 11 \\
\hline HADS Depression & 4 & 2 & 3 & 5.5 & 11 \\
\hline
\end{tabular}

Functional activation analysis. Both the Stroop and Count task resulted in activation of areas within the frontoparietal control network, along with the SMA and pre-SMA, the lateral premotor cortex, and the cerebellum (see Figures 1,2). In addition, there was a predictable activation of the occipital cortex during the Stroop task. Outside of the visual cortex, we found no significant differences between activation patterns during the two tasks. 

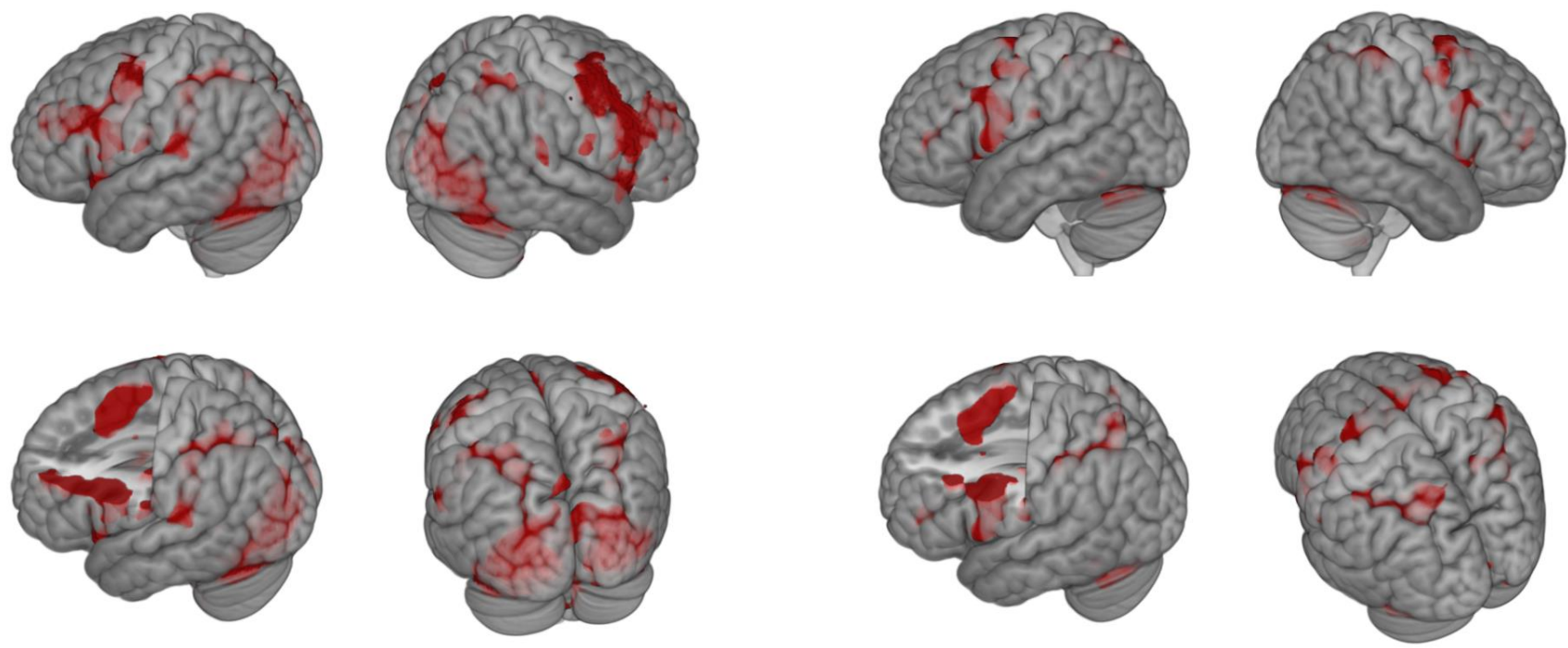

Figure 1. Activation map for the Stroop task $(p<.001$ uncorrected).

Figure 2. Activation map for the Count task $(p<.001$ uncorrected).

\section{Table 2}

Regions of interest within the frontal cortex (MNI coordinates of the center of the cluster).

\begin{tabular}{lcccccc} 
& \multicolumn{3}{c}{ Stroop Task } & \multicolumn{3}{c}{ Count Task } \\
& $\mathrm{x}$ & $\mathrm{y}$ & $\mathrm{z}$ & $\mathrm{x}$ & $\mathrm{y}$ & $\mathrm{z}$ \\
\hline LDLPFC & -37 & 44 & 21 & -41 & 42 & 9 \\
RDLPFC & 33 & 57 & 18 & 38 & 47 & 0 \\
SMA & 2 & -1 & 61 & 0 & -3 & 65 \\
Pre-SMA & -8 & 16 & 48 & -2 & 10 & 54 \\
$\begin{array}{l}\text { L lateral premotor } \\
\text { cortex superior }\end{array}$ & -43 & -3 & 58 & -40 & 2 & 36 \\
$\begin{array}{l}\text { L lateral premotor } \\
\text { cortex inferior }\end{array}$ & -56 & 9 & 12 & -59 & 7 & 9 \\
$\begin{array}{l}\text { R lateral premotor } \\
\text { cortex superior }\end{array}$ & 51 & 4 & 50 & 34 & 4 & 61 \\
$\begin{array}{l}\text { R lateral premotor } \\
\text { cortex inferior }\end{array}$ & 51 & 27 & 26 & 55 & 4 & 41 \\
\hline
\end{tabular}

On the basis of the activation analysis for both the Stroop and Count condition, we identified the following areas within the frontal cortex that were used as ROls for the connectivity analysis: LDLPFC,
RDLPFC, SMA, pre-SMA, and left and right lateral premotor cortex (divided into superior and inferior parts due to elongated form of the clusters; Table 2). 
To evaluate block consistency, a post hoc analysis was performed for the pre-SMA ROI (the selection of this area was influenced by the results of the connectivity analysis, as outlined below). No significant differences were observed between the four task blocks (see Figures 3, 4).

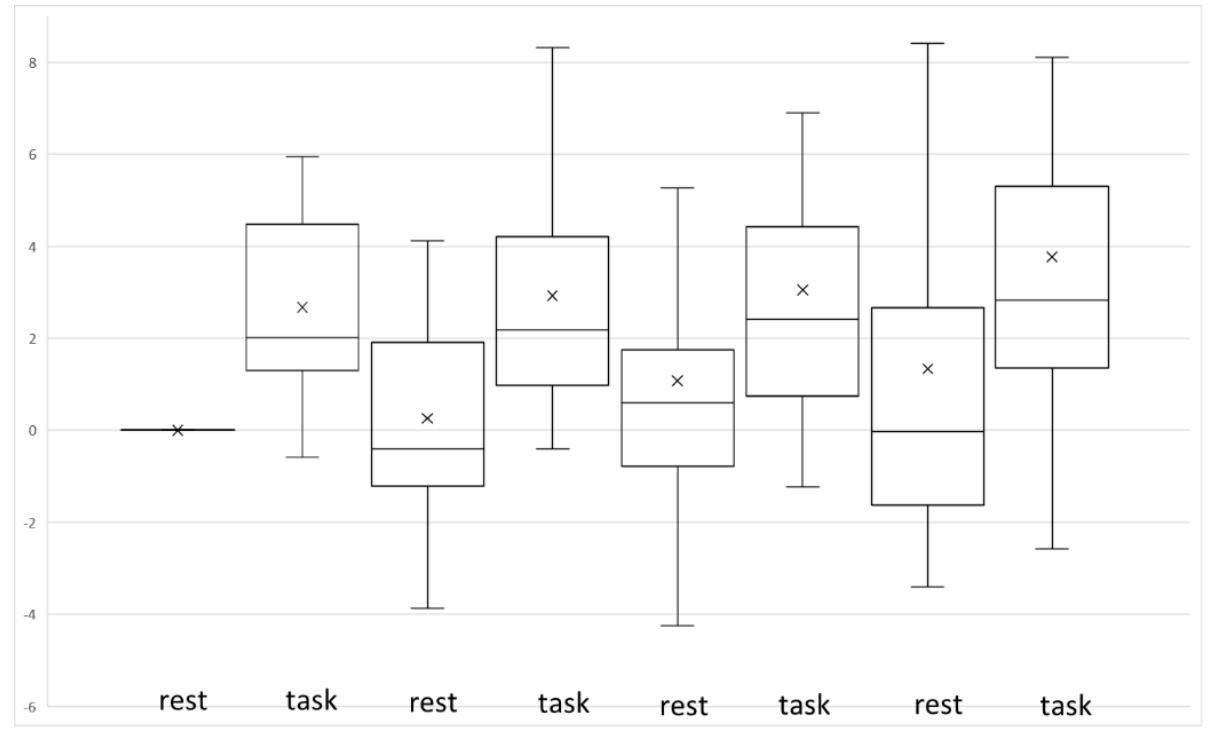

Figure 3. Time course of the activation of the pre-SMA during the Stroop task. Rest and task blocks are shown on the diagram; activation is expressed as the difference from baseline; boxes represent first to third quartile; whiskers represent minimal to maximal values; middle line represents the median; " $x$ " sign represents the mean.

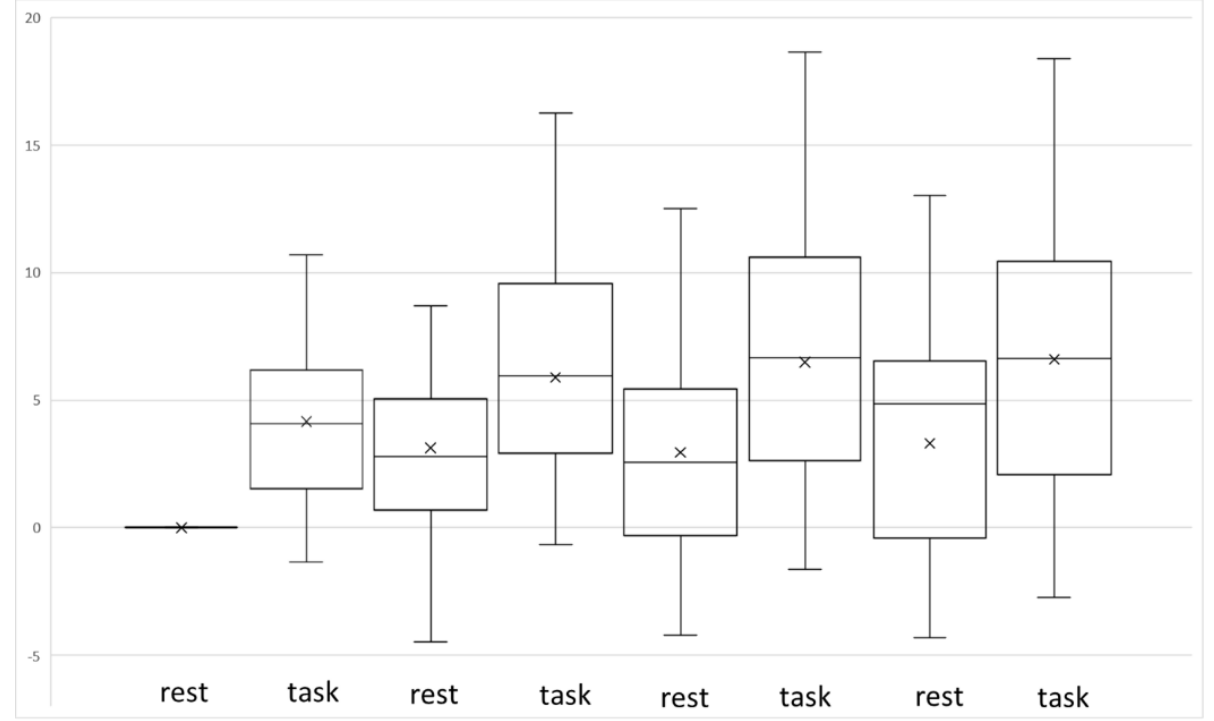

Figure 4. Time course of the activation of the pre-SMA during the Count task. Rest and task blocks are shown on the diagram; activation is expressed as the difference from baseline; boxes represent first to third quartile; whiskers represent minimal to maximal values; middle line represents the median; " $x$ " sign represents the mean. 
Functional connectivity analysis. Both the Stroop and Count task were associated with a widespread increase in connectivity in the pre-SMA, suggesting a major regulatory role of this area (Tables 3 and 4; Figures 5 and 6).
To a lesser extent, there was an increase in connectivity of other premotor areas: the left lateral premotor cortex during the Count task and the right lateral premotor cortex during the Stroop task. The counting task was also associated with functional coupling of the RDLPFC and the posterior cingular cortex.

\section{Table 3}

Connectivity of the frontal cortex during the Stroop task.

\begin{tabular}{|c|c|c|c|c|c|c|c|}
\hline \multirow[t]{2}{*}{ Seed ROI } & \multirow{2}{*}{$\begin{array}{l}\text { Clusters showing an } \\
\text { increase in connectivity } \\
\text { with the seed ROI }\end{array}$} & \multicolumn{3}{|c|}{ Activation peak } & \multirow[t]{2}{*}{ Cluster size } & \multirow{2}{*}{$\begin{array}{l}p \text { (cluster, } \\
\text { FDR- } \\
\text { corrected) }\end{array}$} & \multirow{2}{*}{$\begin{array}{c}p(\text { peak, } \\
\text { uncorrected })\end{array}$} \\
\hline & & $x$ & $y$ & z & & & \\
\hline \multirow{3}{*}{ Pre-SMA } & $\begin{array}{l}\text { L lateral occipital } \\
\text { cortex }\end{array}$ & -32 & -90 & 8 & 463 & $<.001$ & $<.001$ \\
\hline & $\begin{array}{l}\mathrm{R} \text { lateral occipital } \\
\text { cortex }\end{array}$ & 26 & -88 & 8 & 213 & .004 & $<.001$ \\
\hline & $\begin{array}{l}\mathrm{R} \text { paracingulate gyrus, } \\
\text { superior frontal gyrus }\end{array}$ & 8 & 36 & 38 & 167 & .016 & $<.001$ \\
\hline $\begin{array}{l}\mathrm{R} \text { lateral premotor } \\
\text { cortex superior }\end{array}$ & L postcentral gyrus & -42 & -32 & 44 & 86 & .02 & $<.001$ \\
\hline
\end{tabular}

\section{Table 4}

Connectivity of the frontal cortex during the Count task.

\begin{tabular}{|c|c|c|c|c|c|c|c|}
\hline \multirow[t]{2}{*}{ Seed ROI } & \multirow{2}{*}{$\begin{array}{l}\text { Clusters showing an } \\
\text { increase in connectivity } \\
\text { with the seed ROI }\end{array}$} & \multicolumn{3}{|c|}{ Activation peak } & \multirow[t]{2}{*}{ Cluster size } & \multirow{2}{*}{$\begin{array}{l}p \text { (cluster, } \\
\text { FDR- } \\
\text { corrected) }\end{array}$} & \multirow{2}{*}{$\begin{array}{c}p(\text { peak, } \\
\text { uncorrected })\end{array}$} \\
\hline & & $x$ & $y$ & $z$ & & & \\
\hline \multirow{3}{*}{ Pre-SMA } & $\begin{array}{l}\mathrm{R} \text { angular gyrus, } \\
\text { superior parietal lobule, } \\
\text { lateral occipital cortex }\end{array}$ & 40 & -56 & 46 & 267 & .005 & $<.001$ \\
\hline & $\begin{array}{l}\text { L superior temporal } \\
\text { gyrus, planum } \\
\text { temporale, middle } \\
\text { temporal gyrus }\end{array}$ & -66 & -26 & 2 & 190 & .02 & $<.001$ \\
\hline & $\begin{array}{l}\text { R planum temporale, } \\
\text { superior temporal } \\
\text { gyrus }\end{array}$ & 62 & -12 & 4 & 164 & .04 & $<.001$ \\
\hline RDLPFC & $\begin{array}{l}\text { R posterior cingulate } \\
\text { cortex }\end{array}$ & 14 & -50 & 24 & 90 & .03 & $<.001$ \\
\hline $\begin{array}{l}\text { L lateral premotor } \\
\text { cortex superior }\end{array}$ & $\begin{array}{l}\mathrm{R} \text { insular cortex and } \\
\text { putamen }\end{array}$ & 30 & 14 & -4 & 171 & .04 & $<.001$ \\
\hline $\begin{array}{l}\mathrm{L} \text { lateral premotor } \\
\text { cortex inferior }\end{array}$ & R superior frontal gyrus & 8 & 52 & 34 & 346 & $<.001$ & $<.001$ \\
\hline
\end{tabular}



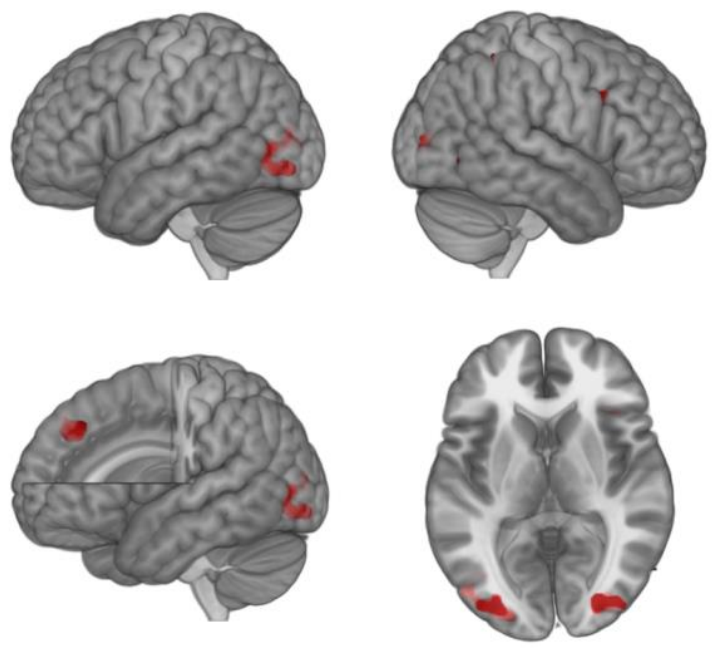

Figure 5. Connectivity map of the pre-SMA during the Stroop task (Stroop vs. rest, $p<.001$ uncorrected at voxel level).

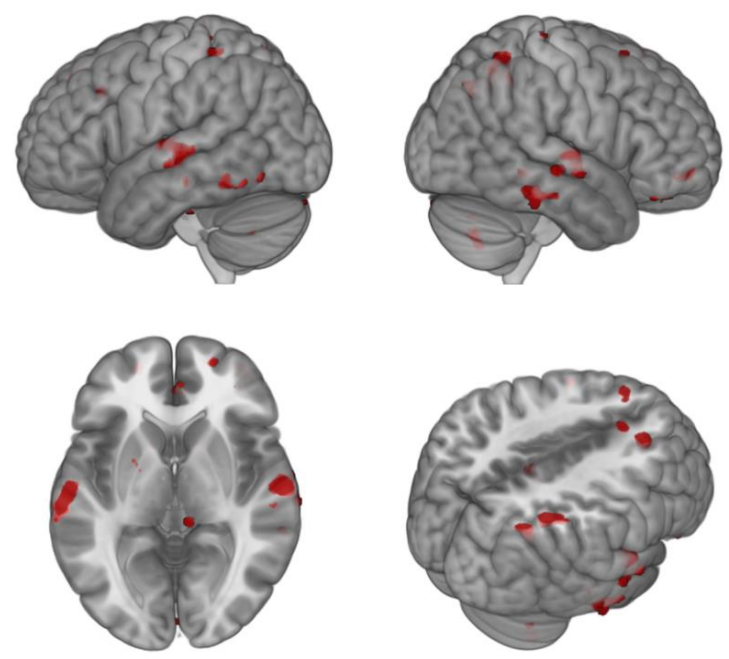

Figure 6. Connectivity map of the pre-SMA during the Count task (Count vs. rest, $p<.001$ uncorrected at voxel level).

\section{Table 5}

Connectivity of the frontal cortex during the Count task: Effects of BRIEF-MoCA value.

\begin{tabular}{llccccccc}
\hline Seed ROI & $\begin{array}{l}\text { Clusters showing an } \\
\text { increase in connectivity } \\
\text { with the seed ROI }\end{array}$ & \multicolumn{2}{c}{ Activation peak } & $\mathrm{y}$ & $\mathrm{z}$ & Cluster size & $\begin{array}{c}p \text { (cluster, } \\
\text { FDR- } \\
\text { corrected) }\end{array}$ & $\begin{array}{c}p \text { (peak, } \\
\text { uncorrected) }\end{array}$ \\
& R and L cuneal cortex & 20 & -72 & 20 & 712 & $<.001$ & $<.001$ \\
LDLPFC & L superior frontal gyrus & -16 & -2 & 68 & 148 & .05 & $<.001$ \\
Pre-SMA & L inferior frontal gyrus & -60 & 16 & 4 & 141 & .05 & .001 \\
SMA & R cuneal cortex & 14 & -74 & 22 & 370 & $<.001$ & $<.001$ \\
& L intracalcarine cortex, & 14 & -68 & 8 & 176 & .02 & $<.001$
\end{tabular}

Next, we evaluated the correlations between the BRIEF-MoCA value and task-based connectivity in the frontal areas. This analysis enabled us to reveal two main effects, both stemming from the counting task (Table 5). The ability to compensate for cognitive decline, measured by the BRIEF-MoCA value, correlated, first, with connectivity in the LDLPFC, and, second, with enrollment of the occipital cortex (Table
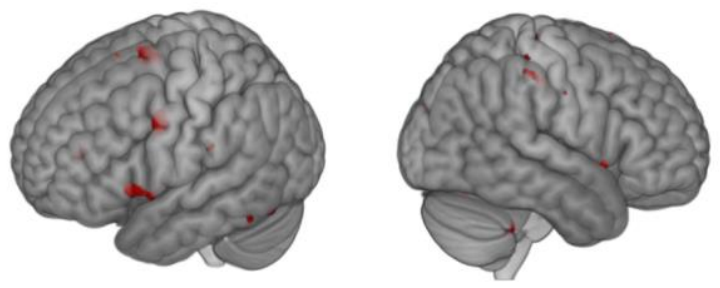
5; Figure 7). To exclude a possible effect of outliers, the main correlation effects were also explored visually (Figures $8 \mathrm{~A}-8 \mathrm{D}$ ).

Figure 7. Connectivity map of the LDLPFC during the Count task: correlation with BRIEF-MoCA value (count vs. rest, effect of BRIEF-MoCA covariate, $p<.001$ uncorrected at voxel level).
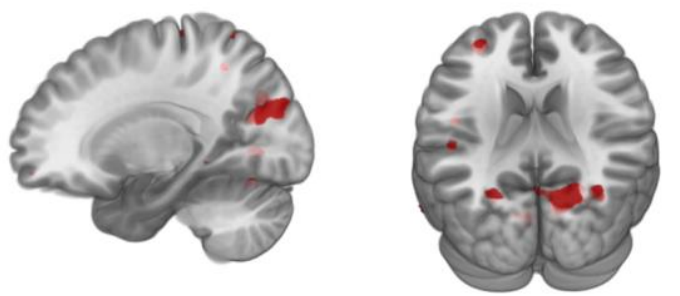


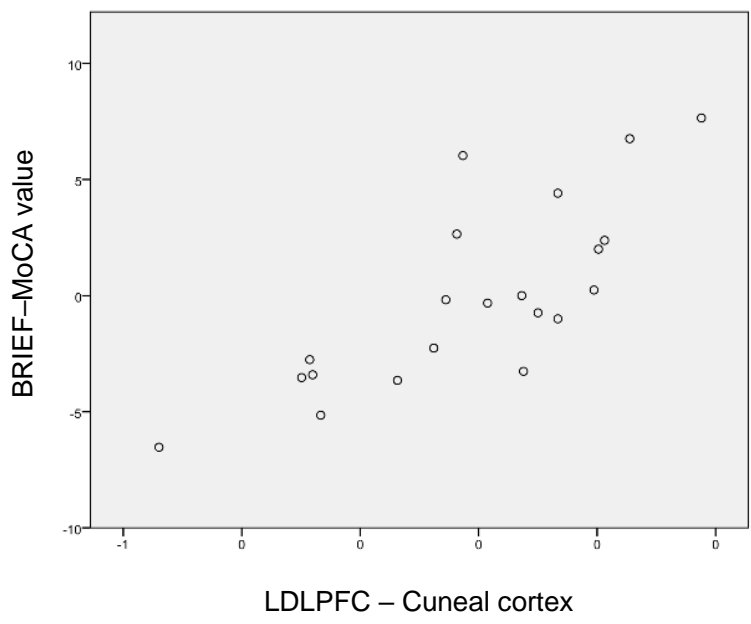

Figure 8A. Correlation of the BRIEF-MoCA value with connectivity in the frontal cortex during the Count task: between the LDLPFC and the cuneal cortex.

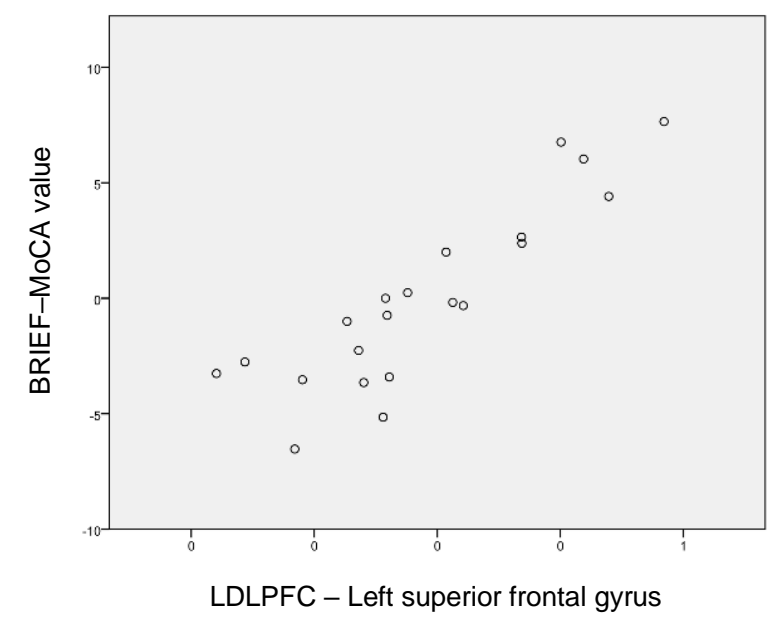

Figure 8 C. Correlation of the BRIEF-MoCA value with connectivity in the frontal cortex during the Count task: between the LDLPFC and the left superior frontal gyrus (SFG).

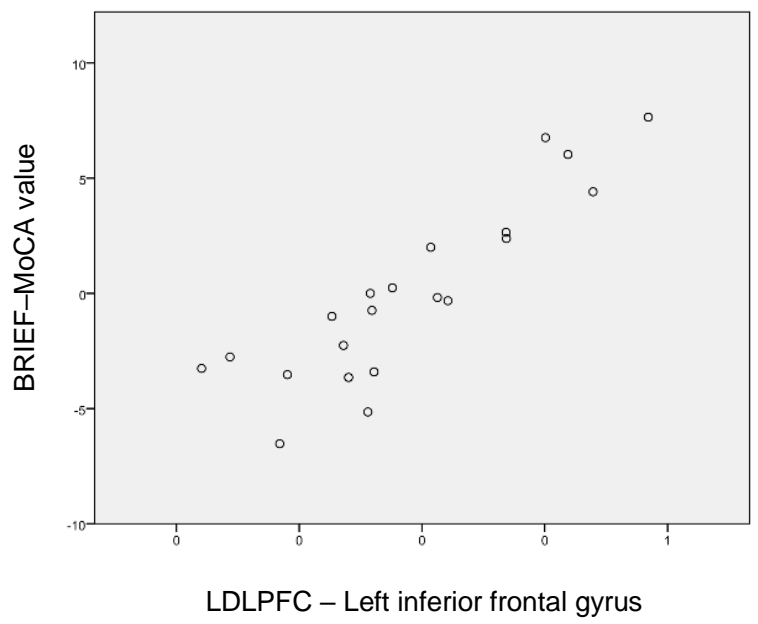

Figure 8B. Correlation of the BRIEF-MoCA value with connectivity in the frontal cortex during the Count task: between the LDLPFC and the left inferior frontal gyrus (IFG).

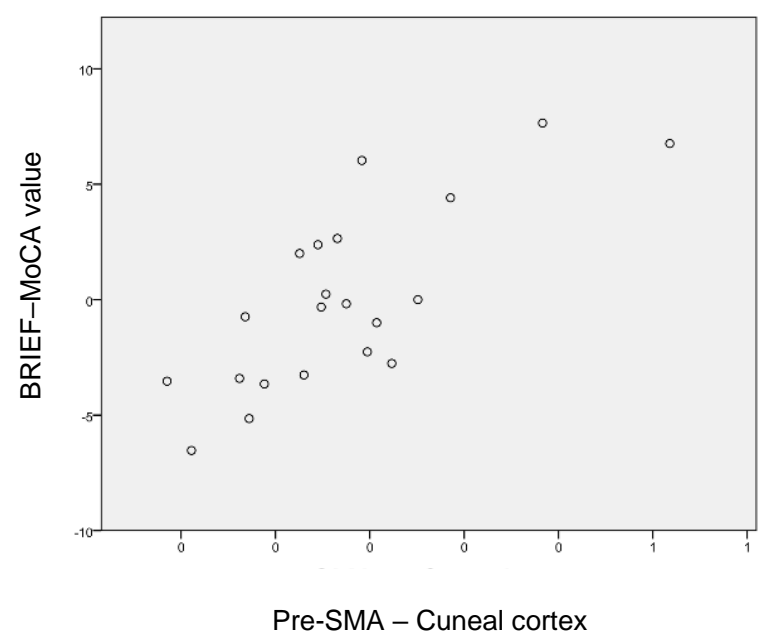

Figure 8D. Correlation of the BRIEF-MoCA value with connectivity in the frontal cortex during the Count task: between the pre-SMA and the cuneal cortex. 


\section{Discussion}

While designing the study, we kept in mind a very practical goal-the possible application of fMRI maps for individualized neuromodulation. Despite the increasing clinical use of rTMS and tDCS, the complex problem of target individualization remains to be solved (Fitzgerald et al., 2009; Luber et al., 2017). First, the preference of the LDLPFC over other functionally salient brain areas is not based on systematic investigation; the correctness of this empirical choice is unknown. Second, the standard method of DLPFC identification-positioning the coil $5 \mathrm{~cm}$ anterior to the motor "hotspot"-is very inaccurate; it allows correct positioning of the coil over the DLPFC in only $36 \%$ of cases (Ahdab, Ayache, Brugières, Goujon, \& Lefaucheur, 2010). Third, the prefrontal cortex is known to be functionally heterogenous; in fact, there are multiple areas within the DLPFC with different functional profiles (Cieslik et al., 2013; Fox, Liu, \& Pascual-Leone, 2013). Mispositioning of the stimulation coil or electrode may interfere with the efficacy of neurostimulation.

To overcome the limitations related to individual variance in structural and functional brain anatomy, navigated TMS can be used. Neuronavigation allows a precise delivery of the stimulus based on neuroimaging, which results in an enhanced efficacy of rTMS, at least in motor applications (Bashir, Edwards, \& Pascual-Leone, 2011). Functional neuroimaging can be used for identification of the salient areas. Both paradigms, Stroop and Count, being easy in comprehension and technically simple, may be implemented in clinical practice for the goal of pretreatment executive function mapping in cognitively impaired patients.

The pattern of activation elicited by both paradigms is typical for brain-level organization of task management (Figures 1, 2). The revealed areas within the frontoparietal control network-the DLPFC and the posterior parietal cortex-participated in highorder regulation. However, the main control region was the secondary motor cortex (lateral premotor, SMA, pre-SMA)-the stereotypical character of the paradigms allowed the delegation of control towards lower-order frontal areas (automatization). The secondary motor cortex is known to participate in various tasks including, but not limited to, motor paradigms (Lima, Krishnan, \& Scott, 2016). While the SMA is responsible for movement generation and control, the pre-SMA supports more complex aspects of action, including action preparation and sequencing (Rizzolatti, Cattaneo, Fabbri-Destro, \&
Rozzi, 2014; Sakai et al., 1999). In general, the revealed patterns of activation were close to the findings of earlier studies (Kaufmann et al., 2008; Naumczyk et al., 2017).

The results of the connectivity analysis support a major regulatory role of the pre-SMA. During the Stroop condition (Figure 5), increased connectivity was seen between the pre-SMA and the lateral occipital cortex, responsible for the synthesis of visual information, and between the pre-SMA and the anterior cingulate cortex, which has been linked to error detection (Bush, Luu, \& Posner, 2000). A different pattern was observed during the Count task (Figure 6). Functional connectivity of the pre-SMA indicated that the task was accomplished with the use of verbal working memory: the superior temporal gyrus is involved in sound processing, and the angular gyrus is responsible for manipulations involving numbers in their verbal form, such as "one", "two", and "three" (Dehaene, Piazza, Pinel, \& Cohen, 2003). As predicted, recruitment of the temporal cortex was seen predominantly on the left side. More surprising, the connectivity between the pre-SMA and the parietal cortex was lateralized towards the right angular gyrus. The right parietal cortex is known to be responsible for number processing that is spatially organized by numerical proximity (Zago et al., 2008). In the current task, the right angular gyrus might be involved in manipulation of the number line that represents a spatial structure.

From a practical point of view, executive tasks used in the fMRI settings are of questionable ecological value: it is unclear to what extent the observed brain functioning reflects its performance in real life. To address this limitation, we included a measure of everyday functioning - the BRIEF questionnaireinto our analysis. We propose that this score is a composite of cognitive capacities per se and of the ability to compensate for existing weaknesses. To clearly separate the second factor, which represents the main target of rehabilitation, we calculated the BRIEF-MoCA value and explored the correlation of this covariate with task-related connectivity in the frontal areas.

The covariate functional connectivity analysis (Table 5) revealed two main findings. First, the ability to compensate for cognitive decline, measured by the BRIEF-MoCA value, correlated with connectivity between the LDLPFC and premotor areas, including the Broca area (Figure 7). The Broca area is involved in the transformation of the sensory representations of words forwarded from the temporal cortex into 
articulatory code (Flinker et al., 2015). It also resolves the conflict between alternative representations in verbal and other domains (Hsu, Jaeggi, \& Novick, 2017). In the Count task, this area might be responsible for the selection and encoding of the correct number in a situation of conflict (e.g., "four" vs. "three") and, thus, has a major regulatory role. The LDLPFC exerts higher-order supervision over the secondary frontal areas, and identical top-down control might serve to compensate for cognitive decline in everyday life. Second, the BRIEF-MoCA value correlated with the enrollment of the medial occipital cortex: cuneal, intracalcarine, and lingual gyrus (Table 5; Figure 7). This phenomenon may reflect compensatory strategies based on the recruitment of an additional modality-visual Arabic representations of numbers (i.e., "1", "2", "3").

The results of our study may be implemented in clinical practice. In order to increase the efficacy of neuromodulation, the target area within the LDLPFC may be identified during pretreatment executive function mapping with the developed modified counting task. The utility of this individualized approach remains to be evaluated in further studies.

\section{Author Disclosure}

Authors have no grants, financial interests, or conflicts to disclose.

\section{References}

Ahdab, R., Ayache, S. S., Brugières, P., Goujon, C., \& Lefaucheur, J.-P. (2010). Comparison of "standard" and "navigated" procedures of TMS coil positioning over motor, premotor and prefrontal targets in patients with chronic pain and depression. Neurophysiologie Clinique = Clinical Neurophysiology, 40(1), 27-36.

Anderkova, L., Eliasova, I., Marecek, R., Janousova, E., \& Rektorova, I. (2015). Distinct pattern of gray matter atrophy in mild Alzheimer's disease impacts on cognitive outcomes of noninvasive brain stimulation. Journal of Alzheimer's Disease, 48(1), 251-260. http://dx.doi.org/10.3233/JAD-150067

Bae, J. B., Han, J. W., Kwak, K. P., Kim, B. J., Kim, S. G., Kim, J. L., ... Kim, K. W. (2018). Impact of mild cognitive impairment on mortality and cause of death in the elderly. Journal of Alzheimer's Disease, 64(2), 607-616. http://dx.doi.org /10.3233/JAD-171182

Bashir, S., Edwards, D., \& Pascual-Leone, A. (2011). Neuronavigation increases the physiologic and behavioral effects of low-frequency rTMS of primary motor cortex in healthy subjects. Brain Topography, 24(1), 54-64. http://dx.doi.org/10.1007/s10548-010-0165-7

Bush, G., Luu, P., \& Posner, M. I. (2000). Cognitive and emotional influences in anterior cingulate cortex. Trends in Cognitive Sciences, 4(6), 215-222. http://dx.doi.org/10.1016/S13646613(00)01483-2

Cieslik, E. C., Zilles, K., Caspers, S., Roski, C., Kellermann, T. S., Jakobs, O., ... Eickhoff, S. B. (2013). Is there "one" DLPFC in cognitive action control? Evidence for heterogeneity from co- activation-based parcellation. Cerebral Cortex, 23(11), 26772689. http://dx.doi.org/10.1093/cercor/bhs256

Clément, F., Gauthier, S., \& Belleville, S. (2013). Executive functions in mild cognitive impairment: Emergence and breakdown of neural plasticity. Cortex, 49(5), 1268-1279. http://dx.doi.org/10.1016/j.cortex.2012.06.004

Dehaene, S., Piazza, M., Pinel, P., \& Cohen, L. (2003). Three parietal circuits for number processing. Cognitive Neuropsychology, 20(3-6), 487-506. http://dx.doi.org/10.1080 /02643290244000239

Delis, D. C., Kaplan, E., \& Kramer, J. H. (2001). Delis-Kaplan Executive Function System (D-KEFS): Examiner's manual. San Antonio, TX: The Psychological Corporation.

Drumond Marra, H. L., Myczkowski, M. L., Maia Memória, C., Arnaut, D., Leite Ribeiro, P., Sardinha Mansur, C. G., ... Marcolin, M. A. (2015). Transcranial magnetic stimulation to address mild cognitive impairment in the elderly: A randomized controlled study. Behavioural Neurology, 2015, 287843. http://dx.doi.org/10.1155/2015/287843

Dubois, B., Slachevsky, A., Litvan, I., \& Pillon, B. (2000). The FAB: A frontal assessment battery at bedside. Neurology, 55(11), 1621-1626. http://dx.doi.org/10.1212/WNL.55.11.1621

Fazekas, F., Chawluk, J. B., Alavi, A., Hurtig, H. I., \& Zimmerman, R. A. (1987). MR signal abnormalities at $1.5 \mathrm{~T}$ in Alzheimer's dementia and normal aging. American Journal of Roentgenology, 149(2), 351-356. http://dx.doi.org/10.2214 /ajr.149.2.351

Fitzgerald, P. B., Hoy, K., McQueen, S., Maller, J. J., Herring, S., Segrave, R., ... Daskalakis, Z. J. (2009). A randomized trial of rTMS targeted with MRI based neuro-navigation in treatmentresistant depression. Neuropsychopharmacology, 34(5), 1255-1262. http://dx.doi.org/10.1038/npp.2008.233

Flinker, A., Korzeniewska, A., Shestyuk, A. Y., Franaszczuk, P. J., Dronkers, N. F., Knight, R. T., \& Crone, N. E. (2015). Redefining the role of Broca's area in speech. Proceedings of the National Academy of Sciences of the United States of America, 112(9), 2871-2875. http://dx.doi.org/10.1073 /pnas.1414491112

Fox, M. D., Liu, H., \& Pascual-Leone, A. (2013). Identification of reproducible individualized targets for treatment of depression with TMS based on intrinsic connectivity. Neurolmage, 66, 151-160. http://dx.doi.org/10.1016/j.neuroimage.2012.10.082

Gioia, G. A., Isquith, P. K., Guy, S. C., \& Kenworthy, L. (2000). TEST REVIEW Behavior Rating Inventory of Executive Function. Child Neuropsychology, 6(3), 235-238. http://dx.doi.org/10.1076/chin.6.3.235.3152

Hsu, N. S., Jaeggi, S. M., \& Novick, J. M. (2017). A common neural hub resolves syntactic and non-syntactic conflict through cooperation with task-specific networks. Brain and Language, 166, 63-77. http://dx.doi.org/10.1016/j.bandl.2016.12.006

Hugo, J., \& Ganguli, M. (2014). Dementia and cognitive impairment: Epidemiology, diagnosis, and treatment. Clinics in Geriatric Medicine, 30(3), 421-442. http://dx.doi.org/10.1016 /j.cger.2014.04.001

Kaufmann, L., Ischebeck, A., Weiss, E., Koppelstaetter, F., Siedentopf, C., Vogel, S. E., ... Wood, G. (2008). An fMRI study of the numerical Stroop task in individuals with and without minimal cognitive impairment. Cortex, 44(9), 12481255. http://dx.doi.org/10.1016/j.cortex.2007.11.009

Lima, C. F., Krishnan, S., \& Scott, S. K. (2016). Roles of supplementary motor areas in auditory processing and auditory imagery. Trends in Neurosciences, 39(8), 527-542. http://dx.doi.org/10.1016/j.tins.2016.06.003

Luber, B. M., Davis, S., Bernhardt, E., Neacsiu, A., Kwapil, L., Lisanby, S. H., \& Strauman, T. J. (2017). Using neuroimaging to individualize TMS treatment for depression: Toward a new paradigm for imaging-guided intervention. Neurolmage, 148, 1-7. http://dx.doi.org/10.1016/j.neuroimage.2016.12.083 
Luria, A. R. (1980). Higher cortical functions in man. Second edition, revised and expanded. New York, NY: Basic Books.

Marshall, G. A., Rentz, D. M., Frey, M. T., Locascio, J. J., Johnson, K. A., Sperling, R. A., \& Alzheimer's Disease Neuroimaging Initiative. (2011). Executive function and instrumental activities of daily living in mild cognitive impairment and Alzheimer's disease. Alzheimer's \& Dementia: The Journal of the Alzheimer's Association, 7(3), 300-308. http://dx.doi.org /10.1016/j.jalz.2010.04.005

Nasreddine, Z. S., Phillips, N. A., Bédirian, V., Charbonneau, S., Whitehead, V., Collin, I., ... Chertkow, H. (2005). The Montreal Cognitive Assessment, MoCA: A brief screening tool for mild cognitive impairment. Journal of the American Geriatrics Society, 53(4), 695-699. http://dx.doi.org/10.1111/j.15325415.2005.53221.x

Naumczyk, P., Sabisz, A., Witkowska, M., Graff, B., Jodzio, K., Gąsecki, D., ... Narkiewicz, K. (2017). Compensatory functional reorganization may precede hypertension-related brain damage and cognitive decline: A functional magnetic resonance imaging study. Journal of Hypertension, 35(6), $1252-1262$. /HJH.0000000000001293

Petersen, R. C., Lopez, O., Armstrong, M. J., Getchius, T. S. D., Ganguli, M., Gloss, D., ... Rae-Grant, A. (2018). Practice guideline update summary: Mild cognitive impairment. Neurology, $\quad 90(3), \quad 126-135 . \quad$ http://dx.doi.org/10.1212 WNL.0000000000004826

Rizzolatti, G., Cattaneo, L., Fabbri-Destro, M., \& Rozzi, S. (2014). Cortical mechanisms underlying the organization of goaldirected actions and mirror neuron-based action understanding. Physiological Reviews, 94(2), 655-706. http://dx.doi.org/10.1152/physrev.00009.2013

Sakai, K., Hikosaka, O., Miyauchi, S., Sasaki, Y., Fujimaki, N., \& Pütz, B. (1999). Presupplementary motor area activation during sequence learning reflects visuo-motor association. The Journal of Neuroscience, 19(10), RC1.

Solé-Padullés, C., Bartrés-Faz, D., Junqué, C., Clemente, I. C., Molinuevo, J. L., Bargalló, N., ... Valls-Solé, J. (2006). Repetitive transcranial magnetic stimulation effects on brain function and cognition among elders with memory dysfunction. A randomized sham-controlled study. Cerebral Cortex, 16(10), 1487-1493. http://dx.doi.org/10.1093/cercor/bhj083

Stroop, J. R. (1935). Studies of interference in serial verbal reactions. Journal of Experimental Psychology, 18(6), 643662. http://dx.doi.org/10.1037/h0054651

Wilson, B. A., Gracey, F., Evans, J. J., \& Bateman, A. (2009). Neuropsychological rehabilitation: Theory, models, therapy and outcome. Cambridge, UK: Cambridge University Press.

Zago, L., Petit, L., Turbelin, M.-R., Andersson, F., Vigneau, M., \& Tzourio-Mazoyer, N. (2008). How verbal and spatial manipulation networks contribute to calculation: An fMRI study. Neuropsychologia, 46(9), 2403-2414. http://dx.doi.org /10.1016/j.neuropsychologia.2008.03.001

Zigmond, A. S., \& Snaith, R. P. (1983). The hospital anxiety and depression scale. Acta Psychiatrica Scandinavica, 67(6), 361370. http://dx.doi.org/10.1111/j.1600-0447.1983.tb09716.x

Received: December 18, 2018

Accepted: December 30, 2018

Published: March 25, 2019 